\title{
EFEITO DE DIFERENTES INTENSIDADES DE DESFOLHA, DA PRÉ-FLORADA, SOBRE A PRODUÇÃO DE CAFÉ CONILON DE VARIEDADE CLONAL
}

\author{
Jhonatas Souza Ventura Tosta ${ }^{1}$ \\ Manuela Arruda Contarine ${ }^{2}$ \\ Julio Cesar Gradice Saluci ${ }^{3}$ \\ Amós Mendes da Silva ${ }^{4}$ \\ Israel Martins Pereira ${ }^{5}$ \\ Rebyson Bissaco Guidinelle ${ }^{6}$ \\ Alex Justino Zacarias ${ }^{7}$ \\ Telma Machado de Oliveira Peluzio ${ }^{8}$ \\ João Batista Esteves Peluzio ${ }^{9}$
}

Resumo: O Brasil é o maior produtor e exportador de café, o que contribui na economia do país. É inquestionável a importância da cafeicultura no agronegócio brasileiro, foram inúmeros trabalhados sobre o aspectos da planta e de seu produto, visando maior eficiência produtiva, que demanda enfolhamento, para maior produtividade.

O objetivo deste trabalho foi avaliar o efeito da intensidade de desfolha na pré-florada sobre a produtividade da planta de café conilon da variedade Vitória, clone $n^{\circ} 7$, sendo desenvolvido no setor de Cafeicultura do Ifes - campus de Alegre. Utilizou-se o delineamento em blocos casualizados, considerando 2 plantas úteis por parcela, com uso de bordaduras. Os tratamentos foram cinco níveis de desfolhas 0, 25, 50, 75 e 100\%. Com as desfolhas de 0, 25, 50 e 75\% não obtiveram prejuízos na produção de chumbinho e chumbões se comparada a desfolha $100 \%$. O mesmo ocorreu com o café depois de colhido e beneficiado.

Palavras-chave: Produtividade; Planta; Intensidade; Tratamentos.

\footnotetext{
1 Instituto Federal do Espírito Santo, Brasil. E-mail: jhonatastosta@gmail.com.

2 Instituto Federal do Espírito Santo, Brasil. E-mail: manucontarine@gmail.com.

3 Instituto Federal do Espírito Santo, Brasil. E-mail: juliosaluci@gmail.com.

4 Instituto Federal do Espírito Santo, Brasil. E-mail: amos_mf13@hotmail.com.

5 Instituto Federal do Espírito Santo, Brasil. E-mail: israelmartins80@gmail.com.

6 Instituto Federal do Espírito Santo, Brasil. E-mail: rebysonguidinelle@gmail.com.

7 Instituto Federal do Espírito Santo, Brasil. E-mail: alexjustino12@gmail.com.

8 Instituto Federal do Espírito Santo, Brasil. E-mail: tmopeluzio@ifes.edu.br.

9 Instituto Federal do Espírito Santo, Brasil. E-mail: jbpeluzio@gmail.com.
} 